\title{
Design of precision variable-rate spray system for unmanned aerial vehicle using automatic control method
}

\author{
Qi Lian ${ }^{1}$, Feng Tan $^{2 *}$, Xiaoming Fu' ${ }^{1}$, Ping Zhang ${ }^{1}$, Xin Liu' ${ }^{1}$, Wei Zhang ${ }^{2}$ \\ (1. College of Engineering, Heilongjiang Bayi Agricultural University, Daqing 163319, Heilongjiang, China; \\ 2. College of Electrical and information, Heilongjiang Bayi Agricultural University, Daqing 163319, Heilongjiang, China)
}

\begin{abstract}
In order to reduce the use of chemical pesticides in crop plant protection and improve the utilization efficiency of pesticides, it is necessary to study advanced application machinery and application techniques. The use of unmanned aerial vehicle (UAV) for pesticide spraying has the characteristics of less application, strong penetrability, wide applicability and flexible operation scheduling, and has gradually become one of the important development directions in the field of aviation plant protection. However, the operation process of the UAV is often affected by meteorological factors and human manipulation, resulting in poor actual operation with inaccurate spray volume and uneven application. Therefore, to improve the stability and uniformity of the application of the plant protection UAV under variable operating conditions, in this paper a real-time control method was proposed for the application flow rate, and a precision variable-rate spray system was designed based on single-chip microcomputer and micro diaphragm pump that can controls the flow rate of the pump in real time with the changes of the operating state. The response s-peed of the variable-rate spray system was tested. The average control response time of the system was $0.18 \mathrm{~s}$, and the average stability time of the pump flow change was $0.75 \mathrm{~s}$. The test results showed that the system has a quick response to the working state and the adjustment of the target flow of the pump can be quickly completed to realize the variable-rate spray function. The research results can provide a reference for the practical application of plant protection UAV variable-rate spray system.
\end{abstract}

Keywords: UAV, plant protection, automatic control, spray system, variable-rate spray, precision application DOI: $10.25165 /$ j.ijabe.20191202.4701

Citation: Lian Q, Tan F, Fu X M, Zhang P, Liu X, Zhang W. Design of precision variable-rate spray system for unmanned aerial vehicle using automatic control method. Int J Agric \& Biol Eng, 2019; 12(2): 29-35.

\section{Introduction}

Currently, pesticide-based chemical control is widely used in agricultural production in China. In addition, plant protection technology and concepts are relatively backward, with a low pesticide use efficiency ${ }^{[1,2]}$, thus causing excessive pesticide use that leads to pesticide waste, soil erosion, and environmental pollution and seriously affects China's food security and sustainable agricultural development. In this regard, the Central Committee of the Communist Party of China has proposed a goal of zero growth in pesticide use by $2020^{[3]}$. To achieve this goal, the development of advanced plant protection equipment and technology is crucial.

The operating efficiency of an unmanned aerial vehicle (UAV) used for plant protection is 100 times better than that of a manual spraying operation and 30 times better than that of small spray equipment ${ }^{[4]}$. Compared with large ground-based plant protection machinery, the operating cost of a UAV is low, and a UAV has a flexible schedule and high adaptability ${ }^{[5-9]}$. Compared with

Received date: 2018-10-08 Accepted date: 2019-03-16

Biographies: Qi Lian, PhD candidate, research interests: agricultural aviation application. Email: qqtt912@yeah.net; Xiaoming Fu, PhD, research interests: agricultural aviation application. Email: dqfxm_1019@163.com; Ping Zhang, PhD candidate, research interests: agricultural aviation application. Email: zhangping217@126.com; Xin Liu, PhD candidate, research interests: agricultural aviation application. Email: 305850334@qq.com; Wei Zhang, PhD, Professor, research interest: agriculture mechanization, Email: zhang66wei@163.com.

*Corresponding author: Feng Tan, PhD, Professor, research interest: artificial intelligence in agricultural. College of Electrical and information, Heilongjiang Bayi Agricultural University, Daqing 163319, Heilongjiang, China. Tel: +86-13836962600, Email: tf1972@163.com. manned agricultural aircraft, UAVs operate at a low working altitude and do not need a designated airfield; therefore, UAVs have been rapidly developed in recent years ${ }^{[10]}$. However, UAV operations are affected by weather, geographical conditions, and human manipulation, which cause unstable operation of the vehicle, resulting in inaccurate and nonuniform pesticide application ${ }^{[11]}$. To improve aerial pesticide spraying accuracy and efficiency, the variable-rate spray technique has been proposed as the direction of future development ${ }^{[12-14]}$. Recently, studies on the variable-rate spray method for ground-based fertilizer and pesticide spraying machines have made remarkable achievements. Deng et al. ${ }^{[15]}$ developed a method for generating two-dimensional and three-dimensional visualizations of the spray distribution that can be used to compare and analyze the spraying effectiveness of the variable-rate spray technique with different methods of control. A variable-rate spray method was also developed for fruit trees in orchards based on the morphology, size and growth of the fruit trees, and a variety of techniques, such as ultrasonic technology, machine vision technology and infrared spectroscopy, were employed to acquire information on the crops. The results showed that the variable-rate spray technique can greatly reduce the pesticide dose and drift ${ }^{[16-18]}$. A pulse width modulation (PWM)-based variable-rate spray system has been designed based on the corn nitrogen content determined from aerial remote sensing images, which controls the amount of the spray of each sprinkler in real time, thus achieving variable-rate nitrogen fertilizer spraying on corn ${ }^{[19]}$. The UAV variable-rate spray technique has also been investigated. Wang et al. ${ }^{[20]}$ developed a variable-rate spray system for UAV. They used a ground-based controller unit to control the airborne spray unit, and the spray volume was regulated via the pulse width control method. Even though the spray 
volume of the UAV was regulated, the flow regulation was performed by human operators based on their own experiences, making it difficult to ensure the accuracy of application. Wu et al. ${ }^{[21]}$ developed a UAV with rotor blades and a remotely controllable variable-rate spray system. That system was characterized by two control modes (remote control and automatic control) that regulate the droplet size of the spray mist. Additionally, the motor speed of the centrifugal sprinkler was regulated according to the set droplet size, ensuring that the droplets maintained a set size at a constant spray flow rate. However, the problem of uneven actual spray deposition is caused by the influence of external factors on the machine remains. Zhang et al. ${ }^{[22]}$ designed a multiple rotors UAV with a variable-rate spray system that operates with a centrifugal pump and a gear pump. The disadvantage of this system is that, after the installation of the gear, the weight of the entire machine is increased, thus shortening the cruise duration. In addition, the mechanical structure of the gear pump is susceptible to wear, i.e., internal structural corrosion is caused by the pesticide, shortening the life of the system.

The above studies show that currently, the variable-rate spray methods that perform real-time image discrimination and control of crop growth and pest infection described above cannot meet the sensitivity and accuracy requirements of aerial plant protection operations at high operating speeds, while the variable-rate spray technique that regulates spray flow according to the changes in the operating state is more suitable for plant protection operations using UAVs. Therefore, in this study, aiming at maintaining the target spray flow with high precision when the target spray volume for the operating area is known, we propose an automatic control method for the variable-rate spray of a UAV that integrates sensors and a micro controller unit (MCU) to achieve real-time control of the spray flow of the pesticide. In this way, precise and even spray of the pesticide is achieved, improving the utilization rate of the pesticide.

\section{Design of the system}

\subsection{System composition and principle}

\subsubsection{System composition}

The primary components of the system are a power unit, a pesticide tank, spray rods and nozzles, a diaphragm pump, a core control panel, a pump motor speed control unit, and a flow sensor, configured as shown in Figure 1.

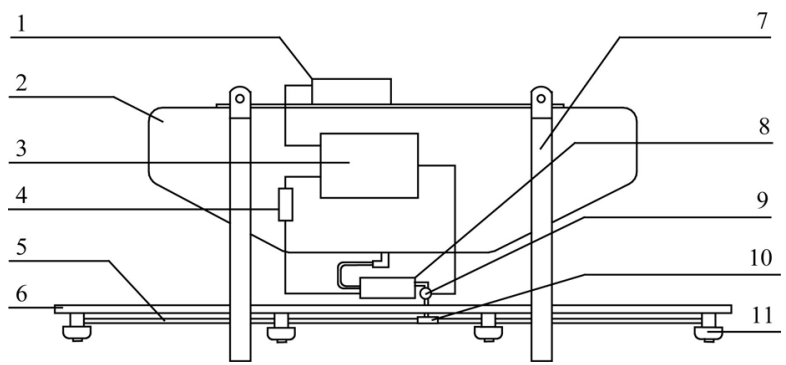

1. Lithium battery 2. Pesticide tank 3. Core control panel 4. Electronic speed control (ESC) 5. Tubing 6. Spray rod 7. Support frame 8. Pump 9. Flow sensor 10. T-joint 11. Fan-shaped nozzle

Figure 1 Variable-spray system structure

The $10 \mathrm{~L}$ pesticide tank is made of resin material, which is lightweight, wear resistant and corrosion resistant. The support frame, which is lightweight and strong, consists of four carbon fiber tubes that connect the spray system to the machine body and support the take-off and landing of the UAV. The spray rod is made of carbon fiber material, fixes each sprinkler, and connects to the support frame. A mini diaphragm pump, small-sized and lightweight with a high spraying pressure, is implemented to pump the pesticide liquid from the tank to each of the sprinklers through the tubing, which is sprayed through the nozzles under a specified pressure. The core control panel uses a Kinetis k60 micro controller made by NXP Semiconductor (Austin, State of Texas, United States of America) as the master chip and integrates the single chip computer, a gyroscope, an accelerometer, a magnetometer, a barometer, and other high-precision sensing components. The pump motor speed is controlled by an electronic governor that controls the spray flow by converting the PWM signal output from the single-chip microcomputer into an equivalent voltage output to the pump. The HOBBYWING Brushless ESC, which has various protection functions, such as start protection, temperature protection, throttle signal loss protection, and overload protection, is used to ensure safe operation of the equipment. To reduce the error between the target flow and the system control outflow, a flow rate sensor is added to monitor the actual outflow. By comparing the actual outflow with the target flow, the differential signal is again transmitted to the ESC to adjust the flow, constituting a complete closed-loop flow control system to improve control accuracy.

\subsubsection{Analysis of the working principle}

When the UAV operates, core control panel 3 monitors the operating state of the UAV in real time, and the needed output flow under the current state is computed by the mathematical model based on the speed and the height of the UAV. The flow output is converted into a pulse signal, which is then transmitted to pump motor governor 4, which further converts the transmitted pulse signal into a PWM signal to control the rotation speed of the pump motor and thus the flow from the pump. The output flow of the pump is acquired by flow sensor 9 and converted into an electrical signal, which is then transmitted to control panel 3. The actual flow and the target flow are compared, and the results are used to perform proportional-integral-derivative (PID) control. The pump control system thereby constitutes a complete closed loop and enables the flow to reach the target value accurately and quickly. The flowchart is shown in Figure 2.

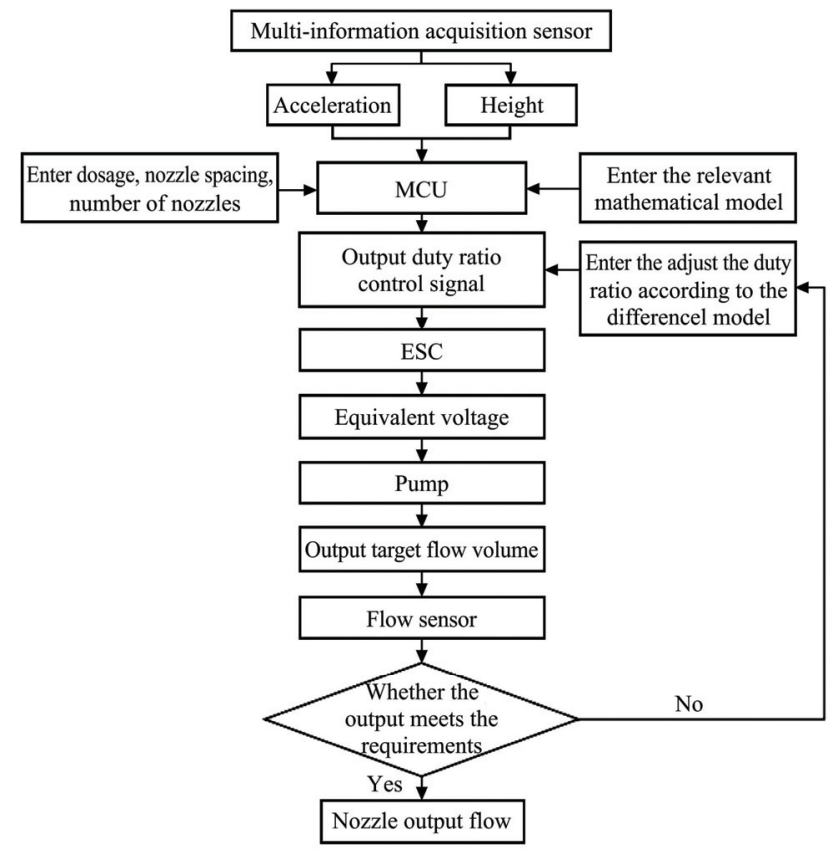

Figure 2 System workflow 


\subsection{System function and implementation method}

\subsubsection{Acquisition of the UAV operating status}

The UAV operating status includes the moving speed, the moving direction, the vehicle altitude, and the vehicle tilt angle ${ }^{[23]}$; currently, the moving speeds of most plant protection UAVs are acquired by the GPS module, which calculates the moving speed based on the moving distance per unit time using Equation (1).

$$
v=\frac{\Delta S}{t}
$$

where, $\Delta S$ is the displacement distance, $\mathrm{m} ; v$ is the moving speed, $\mathrm{m} / \mathrm{s} ; t$ is the time for the displacement to occur, $\mathrm{s}$.

Because the positioning accuracy of the GPS currently used in the UAV for plant protection is low, it is difficult to quickly and accurately measure the speed change in a small displacement range, giving rise to remarkable speed measurement errors. Therefore, a ground differential station is often needed to improve the GPS positioning accuracy ${ }^{[24,25]}$, which is costly and has a limited control range. Some researchers have used image sequences in determining the UAV speed ${ }^{[26]}$, which requires high image clarity and a good photographing environment. These requirements increase the total weight and the structural complexity of the UAV. In this study, the JY-91B 10-axis accelerometer and gyroscope, which are highly responsive, with high precision and a fast computation speed, were employed to perform the speed calculation using the following speed determination formula:

where, $a$ is the acceleration, $\mathrm{m} / \mathrm{s}^{2}$.

$$
v=\int a(t) \mathrm{d} t
$$

To avoid interference from the sway of the UAV body during the actual operation of the flow control of the system, the sensors were integrated with a magnetometer to eliminate the effect of gravity acceleration; therefore, only the acceleration signal along the direction of UAV movement is used to compute the advancing velocity to achieve the operating requirements. To obtain the height information of the UAV, the sensor integrates the air pressure sensing module to obtain the system height ${ }^{[27]}$.

\subsubsection{Development of the flow control model}

To obtain the required volume of pesticide application for a UAV under various working conditions, we must develop a model for the functional relation among the UAV moving speed, the operating height and the required application flow rate. According to the National Standard GB/T17997-2008 on pesticide sprayer field operations ${ }^{[28]}$, the relation among the amount of liquid pesticide, the sprinkler spray rate, the spray range, and the working speed is as follows:

$$
V=600 \frac{Q}{S \cdot W}=600 \frac{n \cdot q}{S \cdot W}
$$

where, $V$ is the volume of pesticide application, $\mathrm{L} / \mathrm{hm}^{2} ; Q$ is the total spray rate of all sprinklers in the spray range, $\mathrm{L} / \mathrm{min} ; S$ is the working speed, $\mathrm{km} / \mathrm{h} ; W$ is the spray range, $\mathrm{m} ; n$ is the number of sprinklers; and $q$ is the spray volume of each sprinkler, $\mathrm{L} / \mathrm{min}$.

The pesticide application volume $(V)$ during the operation is determined by the agronomist according to the actual growth conditions of the crop and the related agronomic requirements, such as the pest infection severity. Therefore, based on the selected amount of pesticide, the UAV moving speed, and the number of sprinklers, the volume of each sprinkler can be calculated as follows:

$$
q=\frac{V \cdot S \cdot W}{600 n}
$$

The spray range $(W)$ of the UAV is primarily determined by the number of sprinklers, the spacing of the sprinklers, the spray angle of the sprinklers, and the spray height, as shown in Figure 3.

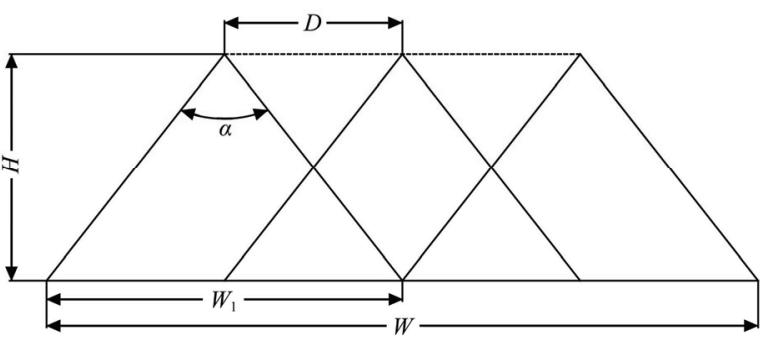

$W$-spray range; $H$-spray height; $D$-sprinkler spacing; $\alpha$-sprinkler spray angle; $W_{1}$-single nozzle spray range.

Figure 3 Spray range diagram

From Figure 3, the calculation formula for the spray range is as follows:

$$
W=D \cdot(n-1)+W_{1}
$$

where, $D$ is the sprinkler spacing, $\mathrm{m} ; W_{1}$ is the single nozzle spray range, $\mathrm{m}$.

Ideally, the single nozzle spray range $\left(W_{1}\right)$ increases with the spray height $(H)$, as indicated by Equation (6):

$$
W_{1}=2 H \cdot \tan \left(\frac{\alpha}{2}\right)
$$

However, in actual operation, as the UAV height increases, the droplet formation of the side sprinklers, which have parabolic trajectories, decreases, and the final moving direction is vertically downward, with a constant spray range. To examine the pattern of change in the spray range as a function of the spray height, in this study, we used the fan-shaped Lechler 110-03 spray nozzle, which has a spray angle of $110^{\circ}$ under the standard operating pressure of $0.25 \mathrm{MPa}$, to conduct spray tests at different heights on a homemade height-adjustable spray platform in the Plant Protection Laboratory of Heilongjiang Bayi Agricultural University. The operating conditions were $24^{\circ} \mathrm{C}$ and $50 \%$ humidity, using water as the test liquid. The mist from the sprinkler was collected by water-sensitive paper under the sprinkler, as shown in Figure 4. The platform can accommodate any type of quick release sprinkler with a spray height adjustment range of $0.05-2.5 \mathrm{~m}$ and a spray pressure of 0-2.5 $\mathrm{MPa}$

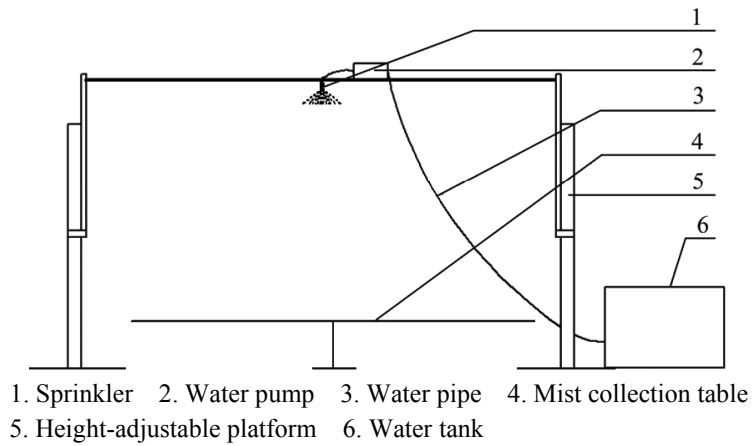

Figure 4 Spray test bench

In the test, a sprinkler is placed at the middle position of the spray rod. According to the common plant protection operation parameters of a multirotor UAV, the starting spray height was set at $0.5 \mathrm{~m}$, which was then raised in $0.05 \mathrm{~m}$ increments until the maximal height of $2 \mathrm{~m}$ was reached; at each height, the test was repeated three times. According to the "Operation quality indicators for agricultural spraying operations" of the "Industry standards of civil aviation of the People's Republic of China", in 
agricultural spraying operations with UAV aircraft, a droplet coverage density on the spray object of greater than $15 / \mathrm{cm}^{2}$ is an effective spray range ${ }^{[29]}$. The total distance traveled by the droplets that reach the water sensitive paper in the effective spray range is measured as the spray range of the sprinkler at that height; the results are shown in Table 1.

Table 1 Change of spray range in different height $(\mathrm{m})$

\begin{tabular}{ccccccccc}
\hline Height & 0.50 & 0.55 & 0.60 & 0.65 & 0.70 & 0.75 & 0.80 & 0.85 \\
\hline Spray range & 1.7 & 1.8 & 2.0 & 2.0 & 2.1 & 2.2 & 2.2 & 2.2 \\
Height & 0.90 & 0.95 & 1.00 & 1.05 & 1.10 & 1.15 & 1.20 & 1.25 \\
Spray range & 2.4 & 2.5 & 2.5 & 2.4 & 2.3 & 2.4 & 2.4 & 2.4 \\
Height & 1.30 & 1.30 & 1.35 & 1.40 & 1.45 & 1.50 & 1.55 & 1.60 \\
Spray range & 2.6 & 2.6 & 2.7 & 2.5 & 2.8 & 2.7 & 2.5 & 2.7 \\
Height & 1.65 & 1.70 & 1.75 & 1.80 & 1.85 & 1.90 & 1.95 & 2.00 \\
Spray range & 2.7 & 2.9 & 2.9 & 2.9 & 2.9 & 2.6 & 2.6 & 2.5 \\
\hline
\end{tabular}

The data in Table 1 are plotted as a scatter plot using the SPSS software, and quadratic function curve fitting was performed. The fitting curve is shown in Figure 5, and the model fitting results are shown in Table 2.

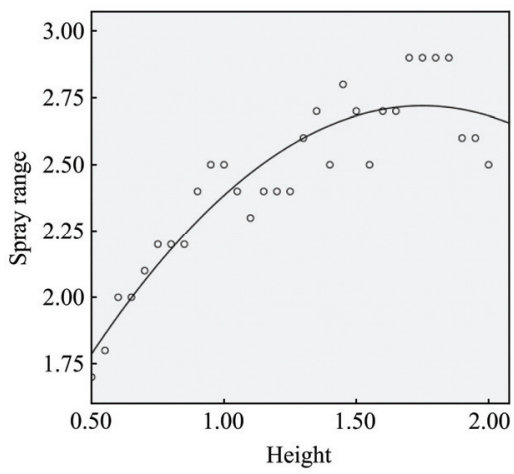

Figure 5 Fitting curve

Table 2 Model test results

\begin{tabular}{|c|c|c|c|c|c|c|c|c|}
\hline \multirow[b]{3}{*}{ Cubic } & \multicolumn{8}{|c|}{ Model summary and parameter estimate } \\
\hline & \multicolumn{4}{|c|}{ Model summary } & \multicolumn{4}{|c|}{ Parameter estimate } \\
\hline & $R^{2}$ & $F$ & $d f 1$ & $d f 2$ & Sig. & Constant & $b 1$ & $b 2$ \\
\hline Function model & 0.854 & 82.08 & 2 & 28 & 0.000 & 0.892 & 2.090 & -0.597 \\
\hline
\end{tabular}

The model test results show that the $F$ value was 82.08 with a SIG of 0.000 , indicating that the model is statistically significant and has variance homogeneity. The parameter estimation results show that the coefficient of the linear term is 2.09 , the coefficient of the quadratic term is -5.17 , and the constant term is 0.892 , as shown in the following equation:

$$
W_{1}=2.09 H-0.597 H^{2}+0.892
$$

Combining Formulas (7) and (5) yields Equation (8):

$$
W=D \cdot(n-1)+3.365 H-5.812 H^{2}+2.694 H^{3}
$$

Combining Equations (8) and (4) yields the formula for the capacity needed by each sprinkler as follows:

$$
q=\frac{V S \cdot\left[D \cdot(n-1)+3.365 H-5.812 H^{2}+2.694 H^{3}\right]}{600 n}
$$

Based on the working principle of the pump, the output flow of the nozzle is regulated by the PWM on the pump pressure; however, the relation between the PWM and the spray flow change is unknown. To examine the effect of the pump duty ratio on the actual sprinkler spray flow, we used a PLD-1206 diaphragm pump and a Lechler 110-01 fan-shaped nozzle to conduct tests. In these tests, different duty ratios were outputted to the pump through an oscilloscope, and the spray volume of the sprinkler was measured. The results show that the duty ratio for the sprinkler to achieve the minimum spray volume was $50 \%$, and the duty ratio was then raised at $1 \%$ increments up to $70 \%$, when the nozzle reached the maximum spray flow volume. The actual spray flow volumes of the Lechler 110-01 nozzle corresponding to different duty ratios are shown in Table 3.

Table 3 Duty ratio relationship with spray flow

\begin{tabular}{cc}
\hline Duty ratio & Spray flow/L $\cdot \mathrm{min}^{-1}$ \\
\hline 0.5 & 0.264 \\
0.51 & 0.342 \\
0.52 & 0.384 \\
0.53 & 0.468 \\
0.54 & 0.504 \\
0.55 & 0.54 \\
0.56 & 0.564 \\
0.57 & 0.594 \\
0.58 & 0.642 \\
0.59 & 0.684 \\
0.6 & 0.702 \\
\hline
\end{tabular}

The designed spray capacities of the sprinkler under different flight heights are calculated using Equation (9). To achieve the target spray capacity, the duty ratio of the pump motor is calculated. The model for the calculation of the required duty ratios for different capacities of the sprinkler and subsequent curve fitting were applied to the data shown in Table 3 to generate the fitted model. To improve the goodness of the fit, we fitted the data using a linear function, an exponential function, a quadratic function and a cubic function in SPSS. The results are shown in Table 4.

Table 4 Curve fitting comparison

\begin{tabular}{lcccc}
\hline \multirow{2}{*}{ Curve type } & \multicolumn{4}{c}{ Model summary } \\
\cline { 2 - 5 } & $R$ & $R^{2}$ & Adjusted $R^{2}$ & Standard error \\
\hline Linear & 0.987 & 0.974 & 0.971 & 0.006 \\
Quadratic Cubic & 0.997 & 0.994 & 0.993 & 0.003 \\
Exponential & 0.997 & 0.994 & 0.992 & 0.003 \\
index & 0.990 & 0.980 & 0.978 & 0.009 \\
\hline
\end{tabular}

The data in Table 4 show that the goodness of the fit is, ordered by quadratic model, cubic model, exponential model and linear model, $0.993>0.992>0.978>0.971$. Therefore, the quadratic model is adopted, with the fitting curve shown in Figure 6, and the model test results are shown in Table 5.

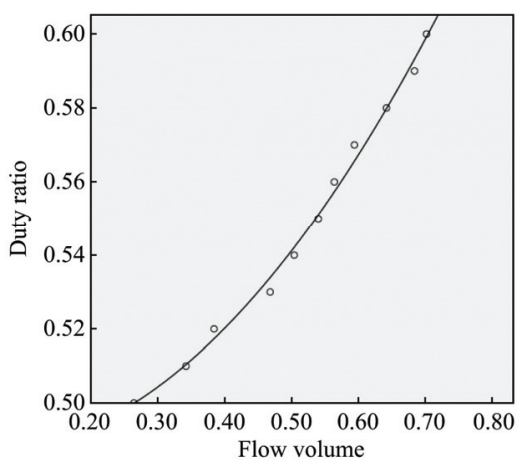

Figure 6 Duty ratio and spray flow 
Table 5 Duty ratio model test table

\begin{tabular}{|c|c|c|c|c|c|c|c|c|}
\hline \multirow[b]{3}{*}{ Quadratic function } & \multicolumn{8}{|c|}{ Model summary and parameter estimate } \\
\hline & \multicolumn{4}{|c|}{ Model summary } & \multicolumn{4}{|c|}{ Parameter estimate } \\
\hline & $R^{2}$ & $F$ & $d f 1$ & $d f 2$ & Sig. & Constant & $b 1$ & $b 2$ \\
\hline Function model & 0.994 & 664.532 & 2 & 8 & 0.000 & 0.488 & -0.021 & 0.256 \\
\hline
\end{tabular}

The model test results show that the $F$ value was 664.532 with a SIG of 0.000 , indicating that this model is statistically significant and has variance homogeneity. The parameter estimation results show that the coefficient of the linear term is -0.021 , the coefficient of the quadratic term is 0.256 , and the constant term is 0.488 , as shown in the following equation:

$$
C=0.256 q^{2}-0.021 q+0.488
$$

where, $C$ is the target duty ratio; $q$ is the target sprinkler capacity.

By combining Equations (9) and (10), we obtain the following calculation model for the required duty ratio:

$$
\begin{aligned}
& C=0.256 \times\left(\frac{V S \cdot\left[D \cdot(n-1)+3.365 H-5.812 H^{2}+2.694 H^{3}\right]}{600 n}\right)^{2} \\
& -0.021 \times\left(\frac{V S \cdot\left[D \cdot(n-1)+3.365 H-5.812 H^{2}+2.694 H^{3}\right]}{600 n}\right)+0.488
\end{aligned}
$$

The calculation model for the duty ratio shown in Equation (11) was exported to the MCU through ARM programming. The pesticide application volume in the operation $(V)$, the number of sprinklers $(n)$, and the spacing of sprinklers $(D)$ are all fixed values that can be entered before the operation, so the required spray flow volume $(q)$ can be achieved by controlling the capacity of the sprinkler through the automatic control of the duty ratio of the pump based on the moving speed $(S)$ and the moving height $(H)$.

\subsubsection{Setting of the flow control range}

As shown in Equation (4), as the moving speed of the UAV increases, the duty ratio of the system increases, as does the spray flow volume. However, limited by the size of the nozzle opening, the flow range of the nozzle under the rated pressure is limited. The flow ranges of the nozzles of different models vary, and to set up an appropriate flow control range of the system, we tested Lechler 110 series nozzles, which are fan-shaped nozzles common used in plant protection UAVs, on an indoor spray test platform, with which the spray capacity ranges of nozzles of different models were measured. The results are shown in Table 6 (when the pressure is higher than $0.4 \mathrm{MPa}$, the flow capacity no longer increases; thus, it is not listed in the table).

Table 6 Spray flow and pressure change table of fan nozzle

$\mathrm{L} \cdot \min ^{-1}$

\begin{tabular}{cccccccc}
\hline \multirow{2}{*}{ Model } & \multicolumn{7}{c}{ Pressure/MPa } \\
\cline { 2 - 8 } & 0.1 & 0.15 & 0.2 & 0.25 & 0.3 & 0.35 & 0.4 \\
\hline $110-015$ & 0.3 & 0.38 & 0.45 & 0.49 & 0.57 & 0.64 & 0.7 \\
$110-02$ & 0.42 & 0.63 & 0.65 & 0.73 & 0.83 & 0.88 & 0.9 \\
$110-03$ & 0.55 & 0.92 & 1.07 & 1.15 & 1.31 & 1.39 & 1.48 \\
$110-04$ & 1.01 & 1.3 & 1.45 & 1.64 & 1.76 & 1.85 & 2.03 \\
$110-05$ & 1.31 & 1.6 & 1.82 & 2.07 & 2.21 & 2.37 & 2.33 \\
\hline
\end{tabular}

\subsubsection{Parameter entry and visualization}

To make the control system suitable for UAVs of different structures used under different operating conditions, we designed a parameter input function for the control system and added physical buttons on the control panel to facilitate the entry of the nozzle specification, the number of sprinklers, the spacing of the sprinklers, the target application volume, etc. We mounted a display module to visualize the input parameters, as shown in Figure 7.

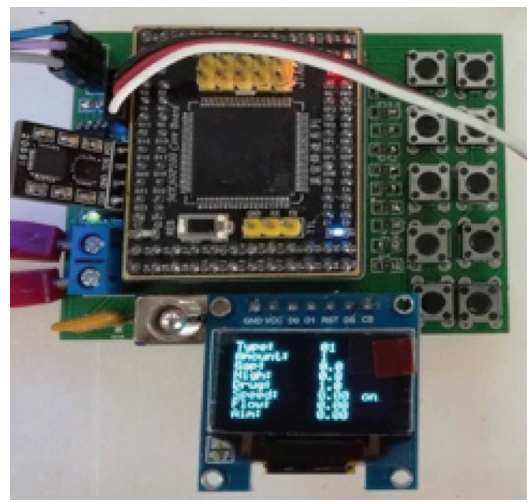

Figure 7 The core control panel

\section{Response test of variable-rate spray control system}

The response speed is an important indicator used to reflect whether the variable-rate spray system meets the requirements of UAV plant protection operations and directly determines the effectiveness of the spray control and the practicability of the system. Therefore, we conducted an indoor response performance test on the system.

\subsection{Objective of the test}

The test is designed to examine the response time of the variable-rate spray control system in controlling the output flow volume with a change in the control signal.

\subsection{Test conditions and equipment}

The test was performed in the Plant Protection Laboratory of the School of Engineering of Heilongjiang Bayi Agricultural University at $20^{\circ} \mathrm{C}$ and $40 \%$ humidity, with water used in place of the pesticide for safety reasons. The test equipment included the variable-rate spray control unit, a water pump, a flow sensor, a power supply, a fan-shaped nozzle (110-01), a water pipe, a measuring cylinder, and a stopwatch.

\subsection{Test plan}

(1) Test1 was designed to examine the response time of the variable-rate spray system and the time it takes to generate a stable spray after acquiring the moving speed information. At the initiation of the test, the moving speed of the system is 0 , and the pump is not started. After the target moving speed is entered, the timing is started. The time at which the pump motor starts is designated Time point 1 , and the time at which the sprinkler starts to form a stable sectorial spray area is designated as Time point 2 . At Time point 2, the pump is turned off and again timed. To reduce the artificial timing error, the above-described test procedure is repeated 10 times, and the average of the samples is used for comparison.

(2) Test2 is designed to examine the time the pump takes to reach the calculated flow volume corresponding to a specific moving speed and the time to stabilize after the variable-rate spray system receives the signal of the varying moving speeds. Teejet 110-01 model fan-shaped nozzles are used on three sprinklers in the test, and the target application volume is set at $15 \mathrm{~L} / \mathrm{hm}^{2}$. At a spray height of $0.8 \mathrm{~m} / \mathrm{s}$, the maximum moving speed of the system is calculated as $4 \mathrm{~m} / \mathrm{s}$ based on the rated flow of the sprinklers. The simulation of the moving speed change is achieved through the designed physical button, in which the initial speed is set at 0 , and the speed is increased in increments of $0.5 \mathrm{~m} / \mathrm{s}$ by pressing on the physical button once. When the speed reaches the maximal speed 
of the system $(4 \mathrm{~m} / \mathrm{s})$, the speed is gradually decreased until the pump stops. The time is started when the speed button is pressed, and the flow volume indicated by the flow rate sensor is recorded. Subsequently, the time point at which the spray flow volume reaches the designed flow volume corresponding to the specific moving speed after the speed is changed is recorded. Each test is repeated ten times, and the average of the samples is used for comparison.

\subsection{Results and analysis}

The results of the pump response test are shown in Table 7 . The average response time of the pump is $0.16 \mathrm{~s}$, and the spray stabilization time is $0.54 \mathrm{~s}$. The control command reaches the pump motor quickly, and its delay is thus considered negligible. However, there is a delay from the response of the mechanical parts of the system, which is determined by the constructed spray implementation system and the performance of the system components. In the proposed system, the mechanical inertia of the diaphragm pump determines the delay characteristics of the spray startup and shutdown, while the mechanical structure and manufacturing process of the nozzle determine the spray stabilization time.

Table 8 shows the time for the system to stabilize at the designed flow volume corresponding to a specific moving speed. The time for the spray flow volume to vary in each speed range was also calculated; the results are shown in Table 9. The average time required for each speed range indicates that as the moving speed of the operation increases, the required flow volume of the target flow volume in the speed range also gradually increases nonlinearly, increasing the time required for the pump to reach the target flow volume. The startup of the pump uses the least time, while stopping the spray uses the most time.

Table 7 Test time for pump response (s)

\begin{tabular}{ccc}
\hline Test number & Time 1 & Time 2 \\
\hline 1 & 0.18 & 0.48 \\
2 & 0.16 & 0.57 \\
3 & 0.19 & 0.48 \\
4 & 0.19 & 0.61 \\
5 & $0 . .16$ & 0.60 \\
6 & 0.18 & 0.55 \\
7 & 0.18 & 0.65 \\
8 & 0.20 & 0.54 \\
9 & 0.18 & 0.48 \\
10 & 0.17 & 0.47 \\
Average & 0.163 & 0.543 \\
\hline
\end{tabular}

Table 8 Time to stability of the system flow (s)

\begin{tabular}{|c|c|c|c|c|c|c|c|c|}
\hline \multirow{2}{*}{$\begin{array}{c}\text { Test } \\
\text { number }\end{array}$} & \multicolumn{8}{|c|}{ Simulation speed $/ \mathrm{m} \cdot \mathrm{s}^{-1}$} \\
\hline & 1 & 2 & 3 & 4 & 3 & 2 & 1 & 0 \\
\hline 1 & 0.35 & 0.83 & 1.59 & 2.31 & 2.98 & 3.51 & 4.18 & 5.22 \\
\hline 2 & 0.38 & 0.87 & 1.63 & 2.37 & 3.05 & 3.55 & 4.20 & 5.33 \\
\hline 3 & 0.39 & 0.84 & 1.71 & 2.43 & 3.00 & 3.47 & 4.19 & 5.27 \\
\hline 4 & 0.36 & 0.88 & 1.61 & 2.37 & 3.07 & 3.59 & 4.27 & 5.43 \\
\hline 5 & 0.39 & 0.86 & 1.59 & 2.41 & 3.04 & 3.64 & 4.22 & 5.28 \\
\hline 6 & 0.40 & 0.85 & 1.46 & 2.42 & 3.07 & 3.73 & 4.31 & 5.36 \\
\hline 7 & 0.32 & 0.83 & 1.43 & 2.60 & 3.15 & 3.77 & 4.24 & 5.37 \\
\hline 8 & 0.44 & 0.89 & 1.76 & 2.41 & 3.06 & 3.61 & 4.28 & 5.42 \\
\hline 9 & 0.33 & 0.87 & 1.68 & 2.37 & 3.09 & 3.61 & 4.19 & 5.37 \\
\hline 10 & 0.41 & 0.84 & 1.56 & 2.29 & 3.04 & 3.56 & 4.22 & 5.40 \\
\hline
\end{tabular}

Table 9 Time for the flow change (s)

\begin{tabular}{|c|c|c|c|c|c|c|c|c|}
\hline \multirow{2}{*}{$\begin{array}{c}\text { Test } \\
\text { number }\end{array}$} & \multicolumn{8}{|c|}{ Speed range $/ \mathrm{m} \cdot \mathrm{s}^{-1}$} \\
\hline & $0-1$ & $1-2$ & $2-3$ & $3-4$ & $4-3$ & $3-2$ & $2-1$ & $1-0$ \\
\hline 1 & 0.35 & 0.48 & 0.76 & 0.72 & 0.67 & 0.53 & 0.67 & 1.04 \\
\hline 2 & 0.38 & 0.49 & 0.76 & 0.74 & 0.68 & 0.5 & 0.65 & 1.13 \\
\hline 3 & 0.39 & 0.45 & 0.87 & 0.72 & 0.57 & 0.47 & 0.72 & 1.08 \\
\hline 4 & 0.36 & 0.52 & 0.73 & 0.76 & 0.7 & 0.52 & 0.68 & 1.16 \\
\hline 5 & 0.39 & 0.47 & 0.73 & 0.82 & 0.63 & 0.6 & 0.58 & 1.06 \\
\hline 6 & 0.4 & 0.45 & 0.61 & 0.96 & 0.65 & 0.66 & 0.58 & 1.05 \\
\hline 7 & 0.32 & 0.51 & 0.6 & 1.17 & 0.55 & 0.62 & 0.47 & 1.13 \\
\hline 8 & 0.44 & 0.45 & 0.87 & 0.65 & 0.65 & 0.55 & 0.67 & 1.14 \\
\hline 9 & 0.33 & 0.54 & 0.81 & 0.69 & 0.72 & 0.52 & 0.58 & 1.18 \\
\hline 10 & 0.41 & 0.43 & 0.72 & 0.73 & 0.75 & 0.52 & 0.66 & 1.18 \\
\hline Average & 0.38 & 0.48 & 0.75 & 0.80 & 0.66 & 0.55 & 0.63 & 1.12 \\
\hline
\end{tabular}

In the tests, the pesticide solution was replaced with water. The properties of the two liquids are slightly different, which should not affect the final actual spray flow volume since the designed system adopts the closed-loop control method, using the calculated flow volume as the ultimate target. Moreover, in actual applications, nozzles with an appropriate opening size are chosen according to the characteristics of the pesticide and the spray requirements to ensure the fluidity of the spray and the control speed of the system. Chen et al. ${ }^{[30]}$ measured the response time of a variable-rate spray system and found that the response times for spray initiation and shutdown were $12 \mathrm{~ms}$ and $16 \mathrm{~ms}$, respectively. However, they did not measure the spray stabilization time, and they used a solenoid valve to control the spray. The sprinkler and pressure device were also different from those used in this study. The variable-rate spray control system designed in this study is able to complete the control operation quickly and achieve a stable, fast and continuously adjustable flow volume, thus meeting the design requirements of the system.

\section{Conclusions}

In this study, we propose a multirotor plant protection UAV-based automatic control method for variable-rate spraying. We construct the control model, which achieves automatic control of the pump flow according to changes in the flight status of the UAV. Compared with the studies on variable-rate spray control of UAVs by Wang et al. and Wu et al., the innovation of this study is that the system aims at maintaining a constant pesticide application volume and achieves the automatic regulation of the spray flow based on the flight status of the UAV.

The results of the response test on the designed control system show that the average response time of the present system is $0.16 \mathrm{~s}$, and the average pump flow stabilization time is $0.54 \mathrm{~s}$, indicating that the system responds quickly, with a stable, rapid and continuously adjustable flow volume.

In future studies, we will further investigate the stabilization method for the acquisition of the UAV status information and the actual operating efficiency of the variable-rate spray control.

\section{Acknowledgements}

The authors acknowledge that the research was financially supported by the graduate student innovation project of Heilongjiang Bayi Agriculture University (YJSCX2017-Z03); the Youth Innovative Talent Program of Heilongjiang Bayi Agriculture University (ZRCQC201802). 


\section{[References]}

[1] He X K, Improving severe draggling actuality of plant protection machinery and its application techniques. Transactions of the CSAE, 2004; 20(1): 13-15. (in Chinese)

[2] Chen S D, Lan Y B, Li J Y, Zhou Z Y, Liu A M, Mao Y D. Effect of wind field below unmanned helicopter on droplet deposition distribution of aerial spraying. Int J Agric \& Biol Eng, 2017; 10(3): 67-77.

[3] Ministry of Agriculture of the People's Republic of China. Zero-growth action plan for pesticide use by 2020. 2015.3.18. (in Chinese)

[4] Zhou Z Y, Zang Y, Luo X W, Lan Y B, Xue X Y. Technology innovation development strategy on agricultural aviation industry for plant protection in China. Transactions of the CSAE, 2013; 29(24): 1-10. (in Chinese)

[5] Yang X J, Yan H R. Current Situation and Development Trend of Equipment for Crop Protection. Transactions of the CSAM, 2002; 33(6): 130-137. (in Chinese)

[6] Kirk I W, Hoffmann W C, Fritz B K. Aerial application methods for increasing spray deposition on wheat heads. Applied Engineering in Agriculture, 2007; 23(6): 357-364.

[7] Zhang J, He X K, Song J L, Zeng A J, Liu Y J, Li X F. Influence of spraying parameters of unmanned aircraft on droplets deposition. Transactions of the CSAM, 2012; 43(12): 94-96. (in Chinese)

[8] Zhang D Y, Lan Y B, Chen L P. Current status and future trends of agricultural aerial spraying technology in China. Transactions of the CSAM, 2014; 45(10): 53-59. (in Chinese)

[9] Tang Q, Zhang R R, Chen L P, Xu M, Yi T C, Zhang B, et al. Droplets movement and deposition of an eight-rotor agricultural UAV in downwash flow field. Int J Agric \& Biol Eng, 2016; 9(5): 24-32

[10] Yang F B, Xue X Y, Zhang L, Sun Z. Numerical simulation and experimental verification on downwash air flow of six-rotor agricultural unmanned aerial vehicle in hover. Int J Agric \& Biol Eng, 2017; 10(4): 41-53.

[11] Ramasamy M, Lee T E, Leishman J G. Flow field of a rotating-wing micro air vehicle. Journal of Aircraft, 2012; 44: 1236-1244.

[12] Lan Y B, Chen S D, Fritz B K. Current status and future trends of precision agricultural aviation technologies. Int J Agric \& Biol Eng, 2017; 10(3): 1-17.

[13] Lan Y, Thomson S J, Huang Y B, Hoffmann W C, Zhang H H. Current status and future directions of precision aerial application for site-specific crop management in the USA. Computers and Electronics in Agriculture, 2010; 74(1): 34-38.

[14] Andrews J. Variable rate spraying--not so far fetched. Farmers Weekly, 2010; 152(6): 64.

[15] Deng W, Huang Y B, Zhao C J, Wang X, Liu J L. Spatial distribution visualization of PWM continuous variable-rate spray. Int J Agric \& Biol Eng, 2013; 6(4): 1-8.
[16] Maghsoudi H, Minaei S. A review of applicable methodologies for variable-rate spraying of orchards based on canopy characteristics. Journal of Crop Protection, 2014; 3(4): 531-542.

[17] K Hu, Z Fu, R Ji, J Wang, Li J Q. Design and development of variable rate spraying system based on canopy volume measurement. IFIP Advances in Information \& Communication Technology, 2016; 368: 402-413.

[18] Chen Y, Ozkan E, Zhu H J, Derksen R, Krause C R. Spray deposition inside tree canopies from a newly developed variable-rate air-assisted sprayer. Transactions of the ASABE, 2013; 56(6): 1263-1272.

[19] Han S, Hendrickson L, Ni B, Robert P C, Rust R H, Larson W E. A variable rate application system for sprayers. International Conference on Precision Agriculture, 2015.

[20] Wang L, Lan Y B, Hoffmann W C, Fritz B K. Design of variable spraying system and influencing factors on droplets deposition of small UAV. Transactions of the CSAM, 2016; 47(1): 15-22. (in Chinese)

[21] Wu T K, Zhou Y C, Xie P. Remote control variable rate sprayer controller system based on PWM. Journal of Agricultural Mechanization Research, 2017; 7: 76-82. (in Chinese)

[22] Zhang J, Chen X. Multi-rotor UAV variable spray system. China Patent 205131680. 2016-04-06. (in Chinese)

[23] Yang J P, Zhu X P. Nonlinear flight control system design of bank-to-turn unmanned aerial vehicle. Acta Armamentarii, 2009; 30(11): 1504-1509. (in Chinese)

[24] Li L, Long S C, Li H J, Zhang L Y. Precise point positioning based on reference station augmentation information. Acta Geodaetica et Cartographica Sinica, 2014; 43(5): 481-485, 492. (in Chinese)

[25] Wu B T, Liu B, Li Y F, Zhang Y. Testing and Analysis on differential GPS aerial drones technology. Journal of Yangtze River Scientific Research Institute, 2017; 34(1): 142-144, 154. (in Chinese)

[26] Yu Q F, Li Q, Lei Z H, Shang Y, Zhu X W, Liu X C. Methods and experiments of velocity measurement of UAV from image sequence. Acta Aeronautica et Astronautica Sinica, 2009; 30(8): 1503-1507. (in Chinese)

[27] Gong X L, Fang J C, Sheng W. A method of intercalibration for GPS and high precision baro-altimeter on line. Journal of Electronics \& Information Technology, 2009; 31(4): 818-821. (in Chinese)

[28] GB/T 17997-2008, Pesticide sprayer field operation procedure and spray quality assessment. (in Chinese)

[29] Civil Aviation Industry Standards of China: Part 1 Agricultural aviation operation quality technical indicators: MH/T 1002-1995. Beijing: Civil Aviation Administration of China, 1995; 11. (in Chinese)

[30] Chen L J, Li Y K. Experimental research on respective cooling measure of glass greenhouse in summer. Journal of Agricultural Mechanization Research, 2010; 32(8): 142-145. (in Chinese) 